\title{
Serum ROBO4 and CLEC14A: preliminary evaluation as diagnostic and progression biomarkers in colorectal cancer patients
}

\author{
Łukasz Pietrzyk ${ }^{1}$ 2, Kamil Torres ${ }^{1}$
}

\begin{abstract}
'Chair and Department of Didactics and Medical Simulation, Medical University of Lublin, Lublin, Poland
${ }^{2}$ Department of General, Oncological, and Minimally Invasive Surgery, $7^{\text {st }}$ Military Clinical Hospital with the Outpatient Clinic, Lublin, Poland
\end{abstract}

Introduction. Colorectal cancer (CRC) is an important global burden, and the discovery of biomarkers for screening and monitoring is a current challenge. The present study aimed to determine the serum concentration of ROBO4 and CLEC14A in CRC patients and assess the diagnostic and progression value of these biomarkers in CRC.

Material and methods. Serum samples were collected from 32 patients with CRC and from 16 healthy individuals. Blood serum of CRC patients were tested before and after surgery. Serum concentration of ROBO4 and CLEC14A were measured using ELISA tests.

Results. The serum concentrations of ROBO4 and CLEC14A were significantly higher in CRC patients than non-cancer controls. The sensitivitiy and specificity of $\mathrm{ROBO} 4$ and $\mathrm{CLEC} 14 \mathrm{~A}$ in distiguishing cancer patients from controls ranged from $71.9 \%$ to $100 \%$ and from $84.5 \%$ to $100 \%$, respectively. The serum ROBO4 concentration was associated with the TNM stage, depth of invasion, and lymph node and distant metastases. The level of ROBO4 was statistically lower 3 months after the surgery, compared to the level noted prior to the operation.

Conclusions. Our preliminary study has provided evidence that ROBO4 and CLEC14A seem to be suitable biomarkers for clinical diagnostic purposes in colorectal cancer.

Key words: ROBO4, CLEC14A, biomarker, colorectal cancer, angiogenesis

\section{Introduction}

Cancer is an important problem in terms of public health. In developed countries with the western diet and lifestyle, cancer causes nearly a quarter of all deaths [1, 2]. Among cancers, colorectal cancer (CRC) is the fourth malignancy most commonly detected worldwide and represents $9.4 \%$ of all cancer incidences in men and $10.1 \%$ in women. In 2018, there were approx. 1.9 million new CRC cases diagnosed worldwide and approx. 0.9 million deaths from colorectal cancer were evidenced [3].
An alarming trend is that CRC patients are shifting younger, e.g. the median age in 2001-2002 vs. 2015-2016 was 72 vs. 66 years at diagnosis [4]. Since colorectal cancer presents clear symptoms only in advanced stages and there are no sensitive and accurate diagnostic methods, the detection of CRC in early stages is problematic and difficult [5]. The main therapies applied for CRC are surgical treatment, chemotherapy, and radiotherapy. Unfortunately, the survival rate is still poor in distant metastatic patients [6]. Even if combined treatments are used,

\section{How to cite:}

Pietrzyk Ł, Torres K. Serum ROBO4 and CLEC14A: preliminary evaluation as diagnostic and progression biomarkers in colorectal cancer patients. NOWOTWORY J Oncol 2022; 72: 1-10. 
a recurrence occurs in approx. 1/3 of cases, and the median survival after surgery with the best supportive care of chemotherapy is up to 24 months [7]. Therefore, the identification of sensitive, reliable, and noninvasive biomarkers as screening tests for CRC would be of great advantage, improving patient outcomes and declining the mortality rate [8]. In particular:

- diagnostic biomarkers indicating the early stage of the disease,

- predictive biomarkers that are crucial for the assessment of the risk of cancer development,

- prognostic biomarkers of the risk of cancer progression are required [6]. However, regardless of many efforts, there are still no adequate biomarkers for accurate prediction and diagnosis of CRC [9].

A critical phase for tumor development and further spread is angiogenesis. Angiogenesis supports tumor growth by the influx of essential nutrients and oxygen to the cancer mass $[10,11]$. It is widely documented that, without new vasculature formation, the maximum size of $1-2 \mathrm{~mm}$ is recognized as the limit for neoplastic expansion [12]. Tumor blood vessels are irregular and differ in their morphology (shape and size) and function from normal vessels. The endothelial cells of tumor blood vessels exhibit overexpression of molecules named tumor endothelial markers (TEMs) [12-14]. Several investigations have indicated that two proteins ( $\mathrm{ROBO} 4$ and CLEC14A) among TEMs are overexpressed on the surface of tumor endothelial cells in a wide range of solid tumors (ovary, prostate, breast, liver, bladder, kidney, and lung) $[15,16]$.

The ROBO4 (magic roundabout 4) protein has been extensively expressed in endothelial cells of various cancer cell lines, including breast and colon cancer, but was not identified in such cell lines as fibroblasts and endometrial stromal cells [17]. Moreover, as shown by immunohistochemistry analysis, $\mathrm{ROBO} 4$ expression was restricted to sites of active formation of new blood vessels [18]. It was found that the $\mathrm{ROBO} 4$ molecule serves a crucial function in tumor neovascularization by initiating vascular endothelial cell migration via specific interaction with ligands (i.e. glycoprotein SLITs) [19, 20]. The involvement of the $\mathrm{ROBO} 4$ protein in pathological angiogenesis indicates that this molecule is a mediator of the tumor growth process [21]. Indeed, it has been proved that blocking ROBO activity can cause inhibition of tumor mass [22].

C-type lectin domain family 14 member A (CLEC14A) is considered to be a TEM due to its overexpression in tumor vasculature, compared to adjacent nontumor blood vessels. High expression of CLEC14A was observed in head and neck squamous cell carcinoma, breast cancers, and clear cell renal cell carcinoma $[23,24]$. Additionally, studies with CLEC14A $(-/-)$ mice proved the promoting role of CLEC14A in tumor growth [24].

Although numerous studies have revealed that activation of $\mathrm{ROBO} 4$ and CLEC14A proteins contributes to angiogenesis and plays a decisive role in tumor growth and metastasis, there are limited reports on the expression of these molecules in tissue or blood in colorectal cancer patients [19-24].

The objective of the present research was to determine the serum concentration of ROBO4 and CLEC14A in colorectal cancer patients. Besides, we tried to assess the relationship between the levels of the biomarkers in serum and the clinicopathological features of CRC patients. The clinical value of $\mathrm{ROBO} 4$ and CLEC14A in diagnosis and progression of colorectal cancer was also evaluated by comparison with the CEA and CA 19.9 markers commonly used in clinical practice.

\section{Materials and methods \\ Patients, clinical diagnosis, ethics}

The study group comprised 48 patients divided into two groups: 32 patients with colorectal cancer (CRC group) and 16 healthy individuals (control group). All CRC patients were diagnosed and underwent cancer surgery between March 2018 and April 2019. The mean age of the CRC patients was $66.14 \pm 9.17$ years (range: 47-82) After surgery, all resected tissues underwent histopathological examination, and the pathologist confirmed CRC in all tissue samples. The primary tumour location was the colon in 18 cases (56\%) and the rectum in 14 cases (44\%). The advancement of the tumour stages was assessed by a highly specialized pathologist according to the staging system (AJCCS) developed by the American Joint Commission on Cancer. Preoperative radiotherapy, chemotherapy, or chemoradiotherapy excluded patients from the examination.

Healthy volunteers (mean age $61 \pm 4.59$ years, range: 44-79years) were recruited from the patients of the Outpatient Clinic of our hospital during a routine colonoscopy screening. The control participants did not take any medical treatment during the study period. In addition, the colonoscopy did not reveal any pathological changes. The characteristics of the patients enrolled in the study are presented in table I.

The study was performed according to the Helsinki Declaration 1964 with later amendments and approved by the Ethical Committee (decision no. KE-0254/180/2017). In accordance with the ethical policy, all participants were adequately informed about the aim and methods of the study. As part of the procedure, all patients signed a written consent form before the initiation of the research.

\section{Sample preparation, biomarker assay}

Venous blood samples ( $10 \mathrm{ml}$ ) were collected into commercially available anticoagulant-treated tubes (EDTA). Blood was taken from the CRC patients at two time points: before the surgery (point 0 ) and postoperatively (point 1), i.e. during the control visit 3 months after the operation. Blood from healthy individuals was sampled only once. The samples were immediately centrifuged at $1000 \times \mathrm{g}$ for $10 \mathrm{~min}$ at $4^{\circ} \mathrm{C}$ and the sera were stored at $-80^{\circ} \mathrm{C}$ until further analysis. The concentrations of ROBO4 and $\mathrm{CLEC} 14 \mathrm{~A}$ in the serum samples were quantified with the use of sandwich ELISA (enzyme-linked immuno- 
Table I. Characteristics of the colorectal cancer (CRC) patient group

\begin{tabular}{|c|c|c|}
\hline Colorectal cancer group & & Number of patients \\
\hline gender & male & 17 \\
\hline & female & 15 \\
\hline tumor location & colon & 18 \\
\hline & rectum & 14 \\
\hline tumor size & $<5.0 \mathrm{~cm}$ & 16 \\
\hline & $\geq 5.0 \mathrm{~cm}$ & 16 \\
\hline TNM stage & $1+\|$ & 18 \\
\hline & $I I I+I V$ & 14 \\
\hline depth of tumor invasion & $\mathrm{T} 1$ & 5 \\
\hline & $\mathrm{T} 2$ & 8 \\
\hline & T3 & 10 \\
\hline & T4 & 9 \\
\hline lymph node metastases & No & 24 \\
\hline (Iv-stage) & $\mathrm{N} 1+\mathrm{N} 2$ & 8 \\
\hline distant metastases (M-stage) & MO & 26 \\
\hline & M1 & 5 \\
\hline lymphovascular invasion & absent & 20 \\
\hline & present & 12 \\
\hline
\end{tabular}

TNM - tumor nodes metastases

sorbent assay) according to the manufacturer's instructions (MyBioSource, San Diego, USA).

The CEA and CA 19.9 serum markers were measured routinely in the CRC patients and controls using a Cobas 6000 analyzer (Roche Diagnostic, North America). CEA and CA 19.9 in the CRC patients were measured at two time points: before and 3 months after the surgery.

\section{Statistical analysis}

The data were shown as descriptive statistics (mean \pm SD; median with minimum and maximum values). Statistical calculations were performed using SPSS software (SPSS 15.0, Chicago, IL, USA) and XLSTAT 2018; Data Analysis and Statistical Solution for Microsoft Excel (Addinsoft, Paris, France, 2017). Prior to the analyses, the data were tested for normal distribution using the Kolmogorov-Smirnov test. As the data indicated non-normal distributions, non-parametric tests were applied to compare the serum biomarker levels between the studied groups and the serum biomarker levels and clinicopathological paramteres. The Mann-Whitney $U$ test was applied to assess the difference between two variable groups, while comparisons among multiple groups were performed using the Kruskal-Wallis test. Receiver-operating characteristic (ROC) curves were used to determine the sensitivity and specificity of serum ROBO4, CLEC14A, CEA, and Ca 19.9. Differences between serum biomarker levels from point 0 to point 1 were evaluated with the Wilcoxon match-pairs signed ranks test. In all analyses, the differences were considered statistically significant when $p<0.05$

\section{Results}

\section{Serum levels of ROBO4 and CLEC14A in CRC patients}

The serum concentration of $\mathrm{ROBO} 4$ and CLEC14A was significantly higher in the CRC patients than in the healthy individuals (fig. 1). The mean $\mathrm{ROBO} 4$ concentration was approx. 2-fold higher in the CRC group, compared to the control $(675.50 \pm 275.28 \mathrm{pg} / \mathrm{ml}$ vs. $339.15 \pm 103.27 \mathrm{pg} / \mathrm{ml}$, respectively), while the mean CLEC14A serum level was approx. 4-fold higher in the CRC patients than in the non-cancer individuals $(50.91 \pm 11.28 \mathrm{ng} / \mathrm{ml}$ vs. $12.45 \pm 5.20 \mathrm{ng} / \mathrm{ml}$, respectively).

Next, the serum levels of ROBO4 and CLEC14A in early-stage (TNM I+II) CRC patients were compared with healthy individuals. The mean serum concentrations of both studied biomarkers were significantly higher in the TNM stage I+II CRC patients than in the controls (fig. 1).

\section{Evaluation of serum ROBO4 and CLEC14A as potential diagnostic biomarkers for CRC}

We used ROC analysis to evaluate the ROBO4 and CLEC14A power in discrimination between patients with CRC and healthy controls (tab. II and fig. 2). The $\mathrm{ROBO} 4$ protein provided 71.9\% sensitivity, $84.5 \%$ specificity, and an AUC of 0.873 (95\% Cl: 0.778-0.968) in diagnosing CRC. The AUC for CLEC14A for discrimination between CRC patients and healthy controls was 1.0; the cutoff value of $23.69 \mathrm{ng} / \mathrm{ml}$ contributed to $100 \%$ sensitivity and specificity. The cutoff value for CEA was $6.89 \mathrm{ng} / \mathrm{ml}$ and provided sensitivity and specificity of 62.5 and $77.0 \%$, respectively (AUC: $0.801 ; 95 \mathrm{Cl}: 0.679-0.992$ ). In the case of CA 19.9, the sensitivity and specificity were $81.3 \%$ and $91.4 \%$, respectively, at the cutoff point of $11.45 \mathrm{ng} / \mathrm{ml}$ (AUC: 0.823 ; 95 Cl: 0.667-0.979).

\section{Relationship between serum levels of ROBO4 and CLEC14A and clinicopathological features in CRC patients}

Table III shows the correlation between serum $\mathrm{ROBO} 4$ and CLEC14A levels and clinicopathological characteristics in CRC patients. The serum $\mathrm{ROBO} 4$ concentration was associated with the TNM stage $(p<0.001)$, depth of invasion (T stage; $\mathrm{p}<0.001$ ), and lymph node ( $\mathrm{N}$ stage; $\mathrm{p}=0.015$ ), distant metastases ( $M$ stage; $p=0.041$ ) and the presence of the lymphovascular invasion $(p=0.034)$. No significant relationship was observed between the CLEC14A concentration in the serum and the clinopathological features (tumor site, lymph node 

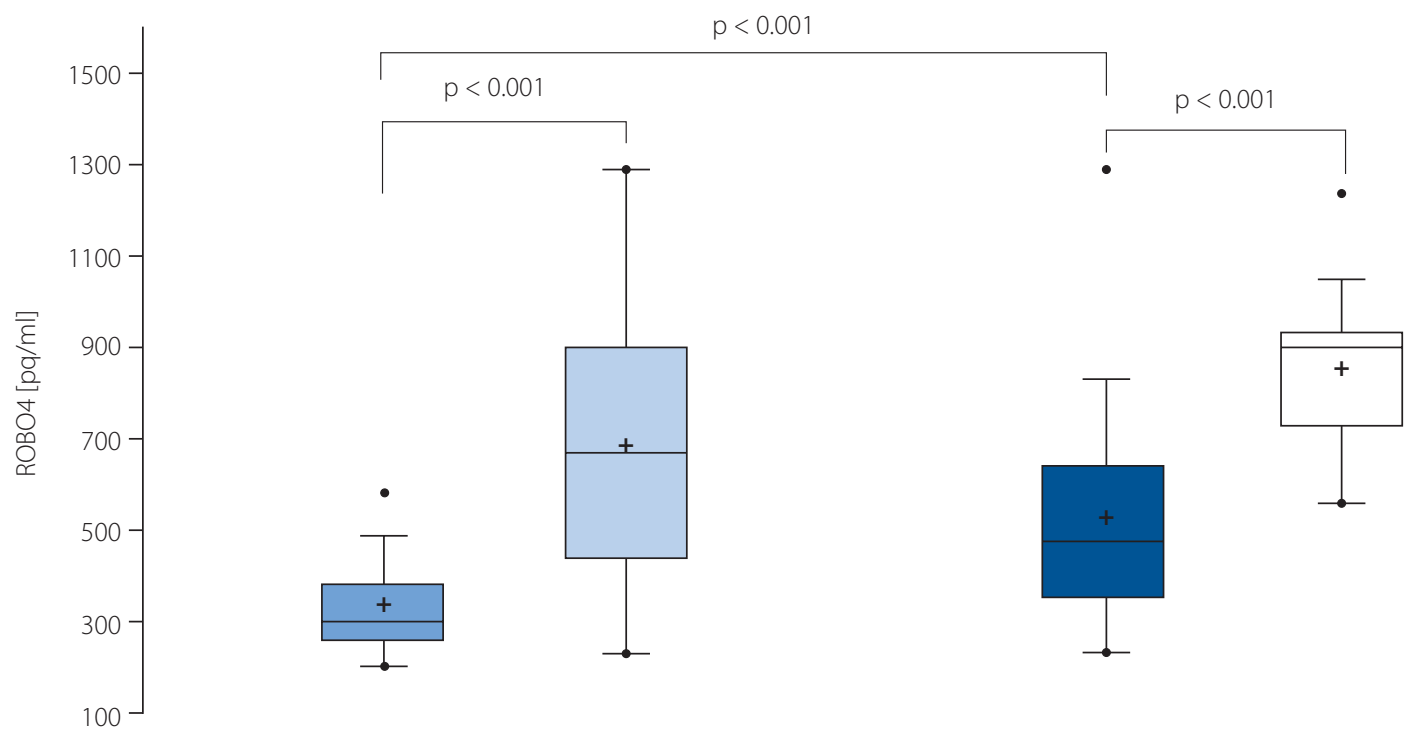

control group $\quad$ CRC group

TNM stage I + II TNM stage III + IV

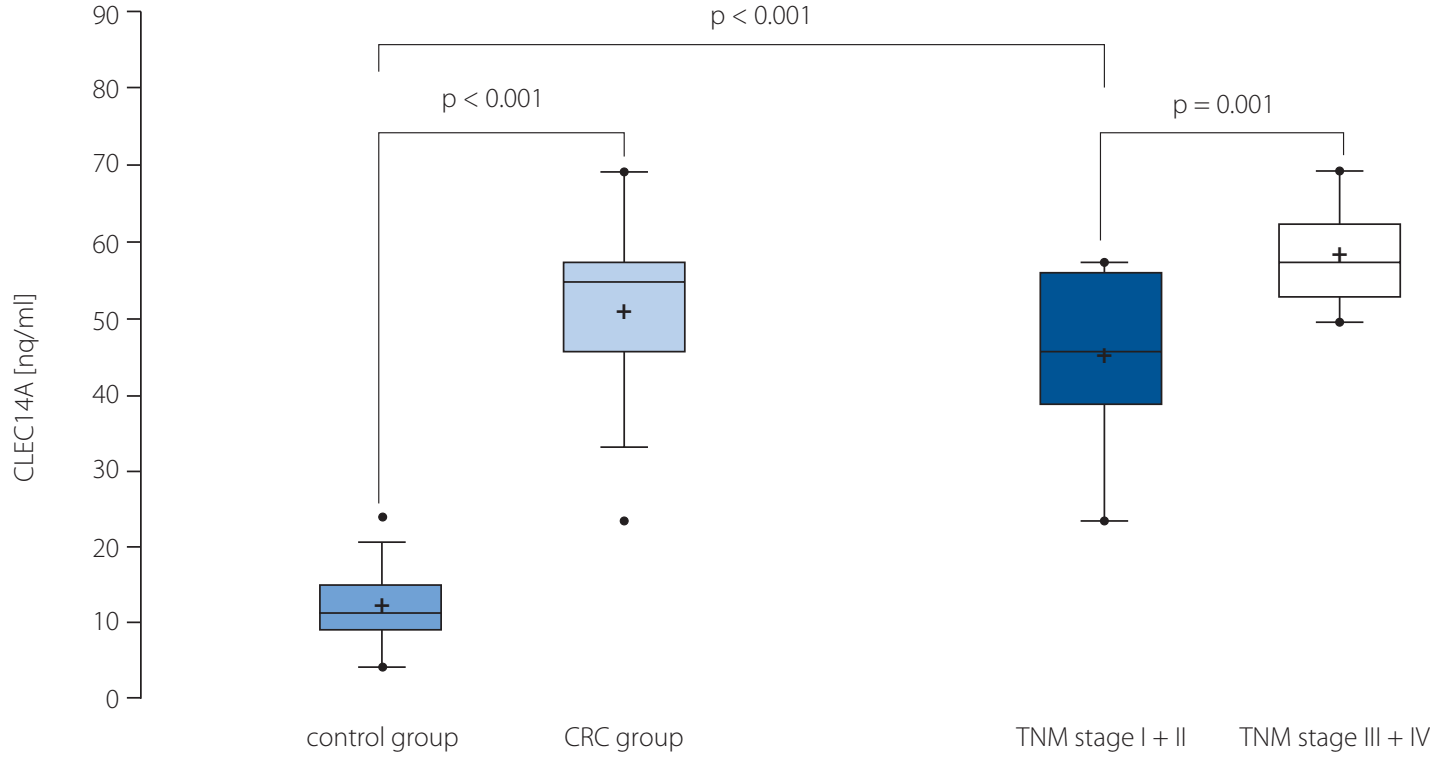

Figure 1. Serum ROBO4 and CLEC14A concentrations in CRC patients and healthy controls

Table II. Diagnostic value of serum ROBO4, CLEC14A, CEA, and CA 19.9 in CRC patients

\begin{tabular}{lcccc}
\hline Factor & Cutoff value & Sensitivity (\%) & Specificity (\%) & $95 \%$ CI \\
\hline ROBO4 & 498.76 & 71.9 & 84.5 & $0.778-0.968$ \\
\hline CLEC14A & 23.69 & 100.0 & 100.0 & $1.0-1.0$ \\
\hline CEA & 6.89 & 62.5 & 77.0 & 0.873 \\
\hline CA 19.9 & 11.45 & 81.3 & 91.4 & $0.679-0.992$ \\
\hline
\end{tabular}

ROBO4 - roundabout4; CLEC14A - C-type lectin family 14 member A; CEA - carcinoembryonic antigen; CA 19.9 - carbohydrate antigen; Cl - confidence interval; AUC - area under the curve

and distant metastases $-\mathrm{N}$ and $\mathrm{M}$ stages; in all cases $\mathrm{p}>0.05$ ). However, the increased CLEC14A levels were associated with the tumor size $(p=0.015)$, TNM stage $(p=0.001)$, and depth of invasion (T stage; $p=0.002$ ).
Postoperative changes in serum ROBO4, CLEC14A, CEA, and CA 19.9 concentrations in CRC patients

Changes of the serum level of ROBO4, CLEC14A, CEA, and CA 19.9 proteins in the postoperative period were assessed 

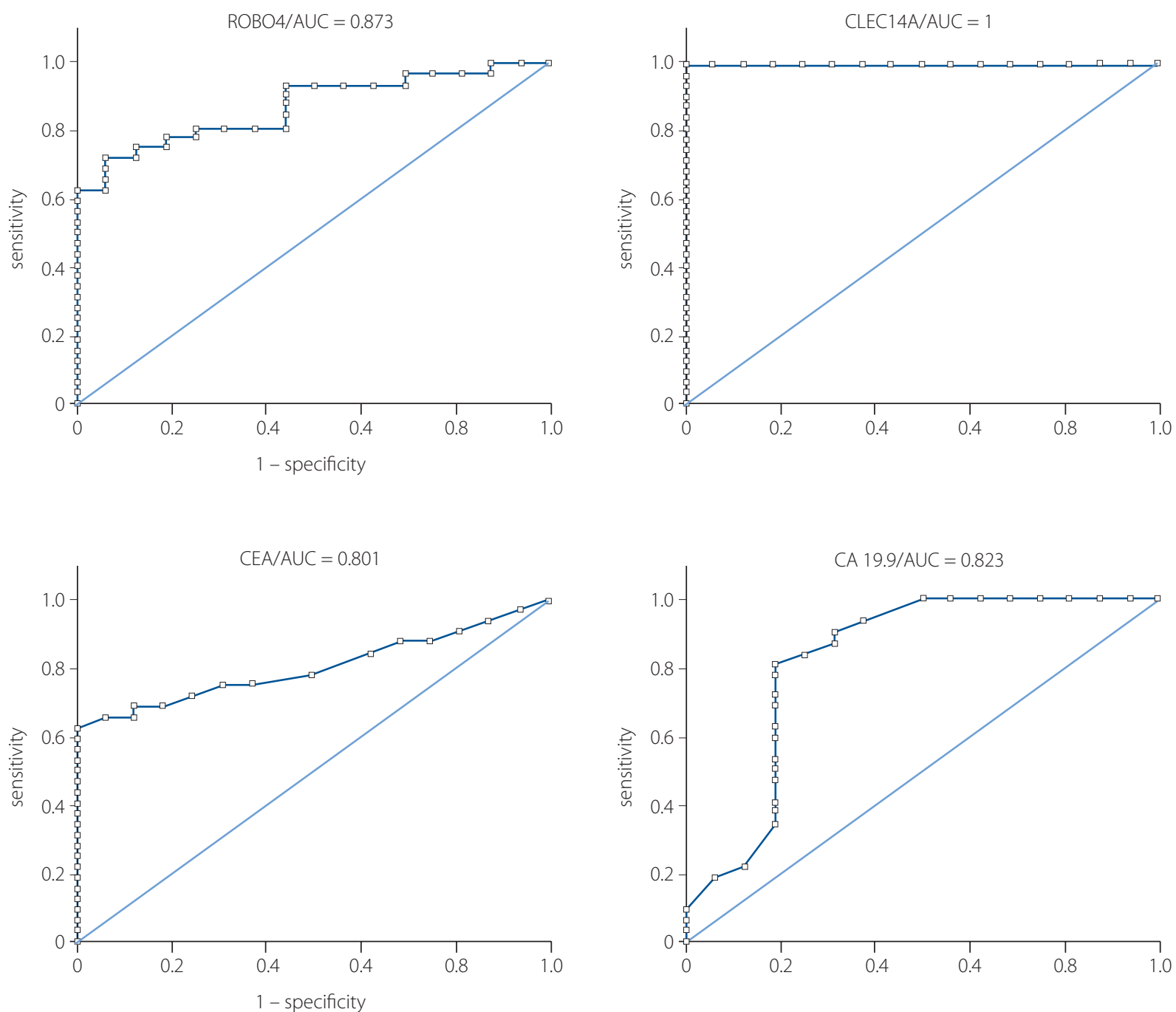

Figure 2. Receiver-operating curve (ROC) for ROBO4, CLEC14A, CEA, and Ca19-9

Table III. Serum concentration of ROBO4 and CLEC14A in relation to the clinicopathological features of CRC patients

\begin{tabular}{|c|c|c|c|c|}
\hline \multicolumn{3}{|c|}{ Colorectal cancer group } & \multirow{2}{*}{$\begin{array}{c}\text { ROBO4 } \\
678.00 \pm 249.05\end{array}$} & \multirow{2}{*}{$\begin{array}{c}\text { CLEC14A } \\
52.28 \pm 10.61\end{array}$} \\
\hline tumor location & colon & mean $\pm S D$ & & \\
\hline & -10 & median & 765.72 & 55.92 \\
\hline & & $\min$ & 234.57 & 23.69 \\
\hline & & $\max$ & 933.59 & 69.37 \\
\hline & rectum & mean \pm sd & $672.27 \pm 315.56$ & $49.16 \pm 12.25$ \\
\hline & & median & 615.20 & 52.60 \\
\hline & & $\min$ & 318.65 & 25.44 \\
\hline & & $\max$ & 1286.69 & 64.73 \\
\hline & Mann-W & est & 0.613 & 0.464 \\
\hline \multirow[t]{4}{*}{ tumor size } & $\begin{array}{l}<5.0 \mathrm{~cm} \\
\mathrm{n}=16\end{array}$ & mean $\pm S D$ & $615.73 \pm 257.57$ & $45.80 \pm 13.07$ \\
\hline & & median & 643.23 & 45.92 \\
\hline & & $\min$ & 279.14 & 23.69 \\
\hline & & $\max$ & 10.47 .06 & 69.37 \\
\hline
\end{tabular}


Table III. cont. Serum concentration of ROBO4 and CLEC14A in relation to the clinicopathological features of CRC patients

\begin{tabular}{|c|c|c|c|c|}
\hline \multicolumn{3}{|l|}{ Colorectal cancer group } & \multirow{2}{*}{$\begin{array}{c}\text { ROBO4 } \\
735.26 \pm 287.49\end{array}$} & \multirow{2}{*}{$\begin{array}{c}\text { CLEC14A } \\
56.02 \pm 6.02\end{array}$} \\
\hline tumor size & $\geq 5.0 \mathrm{~cm}$ & mean $\pm S D$ & & \\
\hline & $11-10$ & median & 744.64 & 56.28 \\
\hline & & $\min$ & 234.57 & 39.71 \\
\hline & & $\max$ & 1286.69 & 66.78 \\
\hline & \multicolumn{2}{|c|}{ Mann-Whitney U test } & 0.341 & 0.015 \\
\hline \multirow[t]{9}{*}{ TNM stage } & \multirow{4}{*}{$\begin{array}{l}1+\| \\
n=18\end{array}$} & mean $\pm S D$ & $538.92 \pm 260.75$ & $45.28 \pm 11.20$ \\
\hline & & median & 476.38 & 45.92 \\
\hline & & $\min$ & 234.57 & 23.69 \\
\hline & & $\max$ & 1286.69 & 58.04 \\
\hline & \multirow{4}{*}{$\begin{array}{l}\text { III + IV } \\
n=14\end{array}$} & mean $\pm S D$ & $851.09 \pm 181.01$ & $58.16 \pm 6.22$ \\
\hline & & median & 904.37 & 57.60 \\
\hline & & $\min$ & 566.96 & 49.78 \\
\hline & & $\max$ & 1239.95 & 69.37 \\
\hline & \multicolumn{2}{|c|}{ Mann-Whitney $U$ test } & $<0.001$ & 0.001 \\
\hline \multirow{17}{*}{$\begin{array}{l}\text { depth of tumor invasion } \\
\text { (T-stage) }\end{array}$} & \multirow{4}{*}{$\begin{array}{l}\mathrm{T1} \\
\mathrm{n}=5\end{array}$} & mean $\pm S D$ & $329.16 \pm 70.40$ & $32.96 \pm 8.35$ \\
\hline & & median & 354.82 & 33.51 \\
\hline & & $\min$ & 234.57 & 23.69 \\
\hline & & $\max$ & 406.52 & 42.47 \\
\hline & \multirow{4}{*}{$\begin{array}{l}\mathrm{T} 2 \\
\mathrm{n}=8\end{array}$} & mean $\pm S D$ & $513.01 \pm 144.74$ & $48.25 \pm 10.24$ \\
\hline & & median & 508.28 & 47.39 \\
\hline & & $\min$ & 318.65 & 32.67 \\
\hline & & $\max$ & 752.71 & 62.62 \\
\hline & \multirow{4}{*}{$\begin{array}{l}\text { T3 } \\
n=10\end{array}$} & mean $\pm S D$ & $699.20 \pm 163.19$ & $54.25 \pm 3.90$ \\
\hline & & median & 727.10 & 56.01 \\
\hline & & $\min$ & 339.32 & 46.07 \\
\hline & & $\max$ & 933.59 & 59.09 \\
\hline & \multirow{4}{*}{$\begin{array}{l}\mathrm{T} 4 \\
\mathrm{n}=9\end{array}$} & mean $\pm S D$ & $986.00 \pm 179.82$ & $59.55 \pm 6.56$ \\
\hline & & median & 926.47 & 58.33 \\
\hline & & $\min$ & 710.54 & 49.78 \\
\hline & & $\max$ & 1286.69 & 69.37 \\
\hline & \multicolumn{2}{|c|}{ Kruskal-Wallis test } & $<0.001$ & 0.002 \\
\hline \multirow{9}{*}{$\begin{array}{l}\text { lymph node metastases } \\
\text { (N-stage) }\end{array}$} & \multirow{4}{*}{$\begin{array}{l}\text { No } \\
n=24\end{array}$} & mean $\pm S D$ & $606.45 \pm 261.68$ & $48.90 \pm 12.15$ \\
\hline & & median & 603.46 & 51.40 \\
\hline & & $\min$ & 234.57 & 23.69 \\
\hline & & $\max$ & 1286.69 & 69.37 \\
\hline & \multirow{4}{*}{$\begin{array}{l}\mathrm{N} 1+\mathrm{N} 2 \\
\mathrm{n}=8\end{array}$} & mean $\pm S D$ & $882.65 \pm 212.62$ & $56.94 \pm 4.82$ \\
\hline & & median & 922.37 & 56.27 \\
\hline & & $\min$ & 594.44 & 49.78 \\
\hline & & $\max$ & 1239.95 & 64.73 \\
\hline & \multicolumn{2}{|c|}{ Mann-Whitney U test } & 0.015 & 0.094 \\
\hline
\end{tabular}


Table III. cont. Serum concentration of ROBO4 and CLEC14A in relation to the clinicopathological features of CRC patients

\begin{tabular}{|c|c|c|c|c|}
\hline \multicolumn{3}{|c|}{ Colorectal cancer group } & \multirow{2}{*}{$\begin{array}{c}\text { ROBO4 } \\
640.51 \pm 262.93\end{array}$} & \multirow{2}{*}{$\begin{array}{c}\text { CLEC14A } \\
50.23 \pm 11.78\end{array}$} \\
\hline \multirow{9}{*}{$\begin{array}{l}\text { distant metastases } \\
\text { (M-stage) }\end{array}$} & \multirow{4}{*}{$\begin{array}{l}\text { MO } \\
n=26\end{array}$} & mean $\pm S D$ & & \\
\hline & & median & 643.23 & 54.65 \\
\hline & & $\min$ & 234.57 & 23.69 \\
\hline & & $\max$ & 1286.69 & 69.37 \\
\hline & \multirow{4}{*}{$\begin{array}{l}M 1 \\
n=5\end{array}$} & mean $\pm S D$ & $920.38 \pm 263.58$ & $55.67 \pm 5.54$ \\
\hline & & median & 923.56 & 55.42 \\
\hline & & $\min$ & 594.44 & 49.78 \\
\hline & & $\max$ & 1239.95 & 62.03 \\
\hline & \multicolumn{2}{|c|}{ Mann-Whitney U test } & 0.041 & 0.457 \\
\hline \multirow{9}{*}{$\begin{array}{l}\text { lymphovascular } \\
\text { invasion }\end{array}$} & \multirow{4}{*}{$\begin{array}{l}\text { absent } \\
n=20\end{array}$} & mean $\pm S D$ & $659.75 \pm 301.20$ & $47.87 \pm 12.46$ \\
\hline & & median & 683.66 & 50.12 \\
\hline & & $\min$ & 234.57 & 23.69 \\
\hline & & $\max$ & 1239.95 & 66.78 \\
\hline & \multirow{4}{*}{$\begin{array}{l}\text { present } \\
n=12\end{array}$} & mean $\pm S D$ & $746.27 \pm 264.06$ & $52.99 \pm 10.21$ \\
\hline & & median & 696.49 & 56.23 \\
\hline & & $\min$ & 439.32 & 25.44 \\
\hline & & $\max$ & 1286.69 & 69.37 \\
\hline & \multicolumn{2}{|c|}{ Mann-Whitney U test } & 0.044 & 0.195 \\
\hline
\end{tabular}

ROBO4 - roundabout4; CLEC14A - C-type lectin family 14 member A; TNM - tumor nodes metastases; SD - standard deviation; min - minimum; max - maximum

(fig. 3). The serum level of ROBO4 and CEA was statistically lower at point 1 (3 months after the surgery) compared to the level noted at point 0 - prior to the operation (point 0 vs. point 1; ROBO4: $675.50 \pm 275.28$ vs. $419.21 \pm 166.98 \mathrm{pg} / \mathrm{ml}$, CEA: $12.07 \pm 8.25$ vs. $7.22 \pm 4.70 \mathrm{ng} / \mathrm{ml}$ ). The serum concentrations of CLEC14A and CA 19.9 decreased in the postoperative time period, compared to the preoperative level; however, the declines were not statistically significant.

\section{Discussion}

In the recent years, there has been increasing interest in identification of CRC with the use of noninvasive biomarkers [8]. The expression of ROBO4 and CLEC14A proteins in tumor neovasculature makes these molecules a potential target for use as a diagnostic and prognostic indicators of cancer, including CRC $[17,23,24]$.

To the best of our knowladge, the present study investigated the serum level of ROBO4 and CLEC14A in colorectal cancer (CRC) patients for the first time. We found that the mean ROBO4 and CLEC14A concentrations in the serum of CRC patients were significantly higher than in the non-cancer controls. Previous literature reports based on immunohistochemical methods evidenced specific endothelial expression of ROBO4 and CLEC14A in various cell lines, i.e. in MCF-7 breast carcinoma and SY-SH-5Y-neuroblastoma cells $[15,17,19]$. Up-regulation of these biomarkers was also proved in human tissues, i.e. in vessels of colorectal liver metastases, bladder and breast carcinoma, and liver and kidney cancer $[15,19,26]$. Moreover, the expression of $\mathrm{ROBO} 4$ and CLEC14A proteins was dominant at sites of active angiogenesis and in regions exposed to hypoxia $[19,27,28]$. In CRC, up-regulation of ROBO4 mRNA was detected in more than $70 \%$ of carcinoma tissues and this protein was exclusively present in the endothelium of cancer vessels [29].

In our study, the ROBO4 and CLEC14A serum levels increased already in early-stage $C R C$, in comparison to the control samples. Moreover, we found that ROBO4 and CLEC14A had high power to discriminate between CRC patients and cancer-free individuals. Interestingly, the diagnostic sensitivity and specificity of serum CLEC14A reached $100 \%$ at the level of $23.98 \mathrm{ng} / \mathrm{ml}$, which is higher than values noted for CEA (sensitivity: $62.5 \%$ and specificity: $77.0 \%$ ) and CA 19.9 (sensitivity: $81.3 \%$ and specificity: $91.4 \%$ ), i.e. biomarkers that are currently commonly used in clinical practice. The high predictive ability of CLEC14A was previously described by Robinson et al., who performed ROC curve analysis of CLEC14A staining scores 

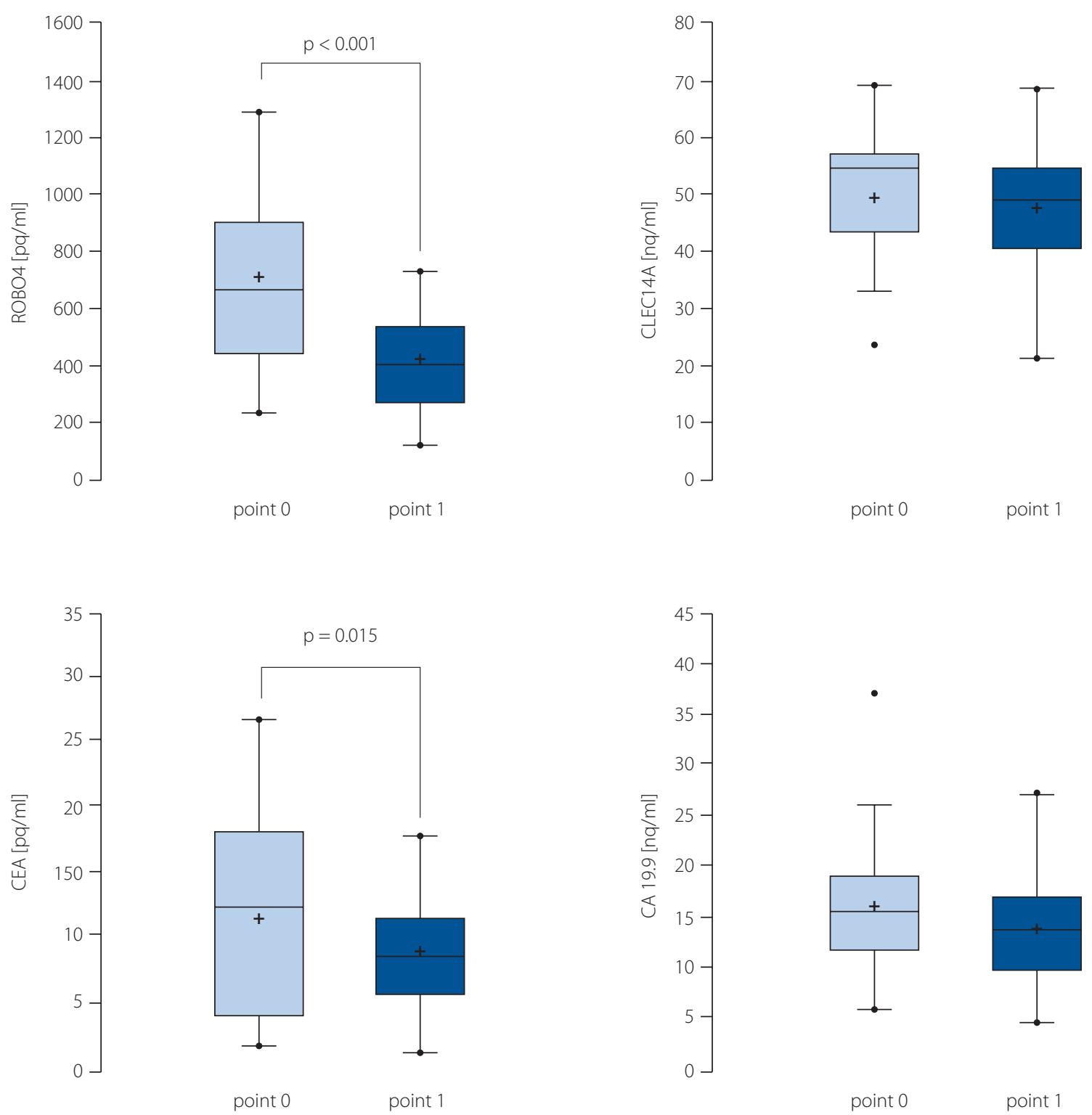

Figure 3. Postoperative changes of serum ROBO4, CLEC14A, CEA, and CA 19.9 concentrations in CRC patients

in various tumor tissues and evidenced their high sensitivity (75\%) and specificity (85\%) in distinguishing between cancer and non-cancer tissue status [30]. The results of our study, together with literature data evidencing that $\mathrm{ROBO} 4$ and $\mathrm{CLE}-$ C14A molecules dominate in tumor endothelial cells, suggest that these biomolecules have diagnostic potential in cancers, presumably including CRC $[15,17,19,30,31]$.

Further, we analyzed the association between the ROBO4 and CLEC14A serum concentrations and clinicopathological features of the CRC patients. In our study, the increased $\mathrm{ROBO} 4$ levels were related to the depth of tumor invasion as well as lymph node and distant metastases. In contrast, the high concentration of CLEC14A was not associated with the presence of lymph node and distant metastases. There is scarce information on the association between $\mathrm{ROBO} 4$ or CLEC14A expression and cancer advancement and prognosis. In prostate cancer, a higher histological tumor (Gleason) score was related to overexpression of $\mathrm{ROBO} 4$ [32]. In acute myeloid leukemia patients, overexpresion of $\mathrm{ROBO} 4$ was a poor prognostic factor and was corelated with shorter disease-free survival and overall survival [33]. Contrasting results were reported by Zhao et al., who evidenced that endothelial overexpression of $\mathrm{ROBO} 4$ suppressed breast cancer angiogenesis and reduced the speed of tumor growth [34]. Simmilary, in non-small lung cancer, high ROBO4 tissue expression was related to good prognosis and was connected with normalization of endothelial cells and reduction of cancer spread [16]. Considering CLEC14A, recent reports indicate that elevated levels of this molecule can inhibit carcinogenesis and progression of lung adenocarcinoma [35]. The expression of ROBO4 or CLEC14A molecules in various cancers tissues 
(up- or down-regulation) suggests that these proteins may act as important modulators of tumorgenesis and tumor progression. Indeed, $\mathrm{ROBO} 4$ and CLEC14A are known as angiogenic factors with an essential role in tumor growth. It was revealed that blocking anti-ROBO4/CLEC14 antibodies induced reduction of the formation of new vessels and led to inhibition of cancer mass $[25,31]$. Currently, the pro-angiogenic properties of CLEC14A and its involvement in tumor growth are well documented $[24,25]$. For example, the CLEC14A protein promotes filopodia formation and activates cell migration, which is detrimental for tumor cell proliferation [15]. Furthermore, the inhibition of the interaction between CLEC14A and multimerin 2 (MMRN2) by a blocking antibody reduces tumor vessel sprouting and hinders the growth of the tumor mass [25].

As a novel observation, we found that the $\mathrm{ROBO} 4$ serum concentrations decreased significantly within 3 months after the surgical removal of CRC. In the case of CLEC14A, we documented a tendency of the serum concentration to decline after the operation. Therefore, we hypothesized that the level of circulating forms of ROBO4 and CLEC14A is associated with the tumor mass. However, we did not find any literatre data to support this hypothesis. We can only speculate that resection of solid tumor mass and removal of existing new vessels that are known to express $\mathrm{ROBO} 4$ and CLEC14A proteins result in a decline in the concentrations of these biomarkers in blood. Prevoiusly, Krishna et al. observed reduction of tumor microvessel CLEC14A expresion after preoperative chemotherapy administered to patients with epithelial ovarian cancer [36]. It is accepted that chemotherapy performed prior to surgical cancer excision contributes to reduction of tumor mass, down staging, and a decrease in the expression of cancer-specific molecules, including tumor endothelial markers [37, 38].

\section{Conclusions}

In this preliminary study, higher serum levels of $\mathrm{ROBO} 4$ and CLEC14A were observed in the CRC patients. Especially, the relationships between ROBO4 and CLEC14A serum levels and TNM stages were assesed and a signinficant post-operative decrease in the serum levels of these biomarkers was demonstrated.

Therefore, ROOB4 and CLEC14A seem to be suitable biomarkers for clinical diagnostic purposes. Nevertheless, due to the preliminary character of our findings, the results have to be taken with caution. In the future, more extensive and prospective studies with a larger CRC patient population seem to be required to validate our results.

Conflict of interest: none declared

\author{
Łukasz Pietrzyk \\ Medical University of Lublin \\ Chair and Department of Didactics and Medical Simulation \\ ul. Chodźki 4 \\ 20-093 Lublin, Poland \\ e-mail: lukasz.pietrzyk@wp.pl
}

Received: 1 Jul 2021

Accepted: $26 \mathrm{Jul} 2021$

\section{References}

1. Brenner $\mathrm{H}$, Chen $\mathrm{C}$. The colorectal cancer epidemic: challenges and opportunities for primary, secondary and tertiary prevention. Br J Cancer. 2018; 119(7): 785-792, doi: 10.1038/s41416-018-0264-x, indexed in Pubmed: 30287914.

2. Siegel RL, Miller KD, Fedewa SA, et al. Colorectal cancer statistics, 2017. CA Cancer J Clin. 2017;67(3): 177-193, doi: 10.3322/caac.21395, indexed in Pubmed: 28248415

3. Bray F, Ferlay J, Soerjomataram I, et al. Global cancer statistics 2018: GLOBOCAN estimates of incidence and mortality worldwide for 36 cancers in 185 countries. CA Cancer J Clin. 2018; 68(6): 394-424, doi: 10.3322/caac.21492, indexed in Pubmed: 30207593

4. Araghi M, Arnold M, Rutherford MJ, et al. Colon and rectal cancer survival in seven high-income countries 2010-2014: variation by age and stage at diagnosis (the ICBP SURVMARK-2 project). Gut. 2021; 70(1): 114-126, doi: 10.1136/gutjnl-2020-320625, indexed in Pubmed: 32482683.

5. Maida M, Macaluso FS, laniro G, et al. Screening of colorectal cancer: present and future. Expert Rev Anticancer Ther. 2017; 17(12): 1131-1146, doi: 10.1080/14737140.2017.1392243, indexed in Pubmed: 29022408

6. Ogunwobi OO, Mahmood F, Akingboye A. Biomarkers in Colorectal Cancer: Current Research and Future Prospects. Int J Mol Sci. 2020; 21(15), doi: 10.3390/ijms21155311, indexed in Pubmed: 32726923.

7. Scheer A, Auer RA. Surveillance after curative resection of colorectal cancer. Clin Colon Rectal Surg. 2009; 22(4): 242-250, doi: 10.1055/s0029-1242464, indexed in Pubmed: 21037815.

8. Patel JN, Fong MKa, Jagosky M. Colorectal Cancer Biomarkers in the Era of Personalized Medicine. J Pers Med. 2019; 9(1), doi: 10.3390/ jpm9010003, indexed in Pubmed: 30646508.

9. Yiu AJ, Yiu CY. Biomarkers in Colorectal Cancer. Anticancer Res. 2016 36(3): 1093-1102, indexed in Pubmed: 26977004.

10. Folkman J. Role of angiogenesis in tumor growth and metastasis. Semin Oncol. 2002; 29(6 Suppl 16): 15-18, doi: 10.1053/sonc.2002.37263, indexed in Pubmed: 12516034.

11. Naumov GN, Akslen LA, Folkman J. Role of angiogenesis in human tumor dormancy: animal models of the angiogenic switch. Cell Cycle. 2006; 5(16): 1779-1787, doi: 10.4161/cc.5.16.3018, indexed in Pubmed: 16931911.

12. Pietrzyk Ł. Biomarkers Discovery for Colorectal Cancer: A Review on Tumor Endothelial Markers as Perspective Candidates. Dis Markers. 2016; 2016: 4912405, doi: 10.1155/2016/4912405, indexed in Pubmed: 27965519.

13. Pietrzyk $€$, Wdowiak P. Endosialin (TEM1) as a Diagnostic, Progression, and Prognostic Serum Marker for Patients With Colorectal Cancer-A Preliminary Study. Cancer Control. 2020; 27(1): 1073274820903351 , doi: 10.1177/1073274820903351, indexed in Pubmed: 32107922

14. Pietrzyk $\measuredangle$, Wdowiak P. Serum TEM 5 and TEM7 concentrations correlate with clinicopathologic features and poor prognosis of colorectal cancer patients. Adv Med Sci. 2019; 64(2): 402-408, doi: 10.1016/j. advms.2019.07.001, indexed in Pubmed: 31352222.

15. Mura M, Swain RK, Zhuang $X$, et al. Identification and angiogenic role of the novel tumor endothelial marker CLEC14A. Oncogene. 2012; 31(3): 293-305, doi: 10.1038/onc.2011.233, indexed in Pubmed: 21706054.

16. Pircher A, Fiegl $M$, Untergasser $G$, et al. Favorable prognosis of operable non-small cell lung cancer (NSCLC) patients harboring an increased expression of tumor endothelial markers (TEMs). Lung Cancer. 2013; 81(2): 252-258, doi: 10.1016/j.lungcan.2013.04.014, indexed in Pubmed: 23664449.

17. Seth P, Lin Y, Hanai Ji, et al. Magic roundabout, a tumor endothelial marker: expression and signaling. Biochem Biophys Res Commun. 2005; 332(2): 533-541, doi: 10.1016/j.bbrc.2005.03.250, indexed in Pubmed: 15894287.

18. Pircher A, Schäfer G, Eigentler A, et al. Robo 4 - the double-edged sword in prostate cancer: impact on cancer cell aggressiveness and tumor vasculature. Int J Med Sci. 2019; 16(1): 115-124, doi: 10.7150/ ijms.28735, indexed in Pubmed: 30662335.

19. Huminiecki L, Gorn M, Suchting S, et al. Magic roundabout is a new member of the roundabout receptor family that is endothelial specific and expressed at sites of active angiogenesis. Genomics. 2002; 79(4): 547-552, doi: 10.1006/geno.2002.6745, indexed in Pubmed: 11944987.

20. Park KW, Morrison CM, Sorensen LK, et al. Robo4 is a vascular-specific receptor that inhibits endothelial migration. Dev Biol. 2003; 261(1): 
251-267, doi: 10.1016/s0012-1606(03)00258-6, indexed in Pubmed: 12941633.

21. Huminiecki L. Magic roundabout is an endothelial-specific ohnolog of ROBO1 which neo-functionalized to an essential new role in angiogenesis. PLOS ONE. 2019; 14(2): e0208952, doi: 10.1371/journal. pone.0208952.

22. Wang B, Xiao Y, Ding BB, et al. Induction of tumor angiogenesis by Slit-Robo signaling and inhibition of cancer growth by blocking Robo activity. Cancer Cell. 2003; 4(1): 19-29, doi: 10.1016/s1535-6108(03)00164-8, indexed in Pubmed: 12892710.

23. Masiero $M$, Simões FC, Han HD, et al. A core human primary tumor angiogenesis signature identifies the endothelial orphan receptor ELTD1 as a key regulator of angiogenesis. Cancer Cell. 2013; 24(2): 229-241, doi: 10.1016/j.ccr.2013.06.004, indexed in Pubmed: 23871637.

24. Borah S, Vasudevan D, Swain RK. C-type lectin family XIV members and angiogenesis. Oncol Lett. 2019; 18(4): 3954-3962, doi: 10.3892/ ol.2019.10760, indexed in Pubmed: 31579078.

25. Noy PJ, Lodhia P, Khan K, et al. Blocking CLEC14A-MMRN2 binding inhibits sprouting angiogenesis and tumour growth. Oncogene. 2015; 34(47): 5821-5831, doi: 10.1038/onc.2015.34, indexed in Pubmed: 25745997.

26. Winslow S, Lindquist KE, Edsjö A, et al. The expression pattern of matrix-producing tumor stroma is of prognostic importance in breast cancer. BMC Cancer. 2016; 16(1): 841, doi: 10.1186/s12885-016-2864-2, indexed in Pubmed: 27809802.

27. Jiang Z, Liang G, Xiao Y, et al. Targeting the SLIT/ROBO pathway in tumor progression: molecular mechanisms and therapeutic perspectives. Ther Adv Med Oncol. 2019; 11: 1758835919855238, doi: 10.1177/1758835919855238, indexed in Pubmed: 31217826.

28. Lee $\mathrm{S}$, Rho SS, Park H, et al. Carbohydrate-binding protein CLEC14A regulates VEGFR-2- and VEGFR-3-dependent signals during angiogenesis and lymphangiogenesis. J Clin Invest. 2017; 127(2): 457-471, doi: 10.1172/JCl85145, indexed in Pubmed: 27991863.

29. Gröne J, Doebler O, Loddenkemper C, et al. Robo1/Robo4: differential expression of angiogenic markers in colorectal cancer. Oncol Rep. 2006; 15(6): 1437-1443, indexed in Pubmed: 16685377.
30. Robinson J, Whitworth $\mathrm{K}$, Jinks $\mathrm{E}$, et al. An evaluation of the tumour endothelial marker CLEC14A as a therapeutic target in solid tumours. J Pathol Clin Res. 2020; 6(4): 308-319, doi: 10.1002/cjp2.176, indexed in Pubmed: 32696621.

31. Dai C, Gong Q, Cheng Y, et al. Regulatory mechanisms of Robo4 and their effects on angiogenesis. Biosci Rep. 2019; 39(7), doi: 10.1042/ BSR20190513, indexed in Pubmed: 31160487.

32. Pircher A, Schäfer G, Eigentler A, et al. Robo 4 - the double-edged sword in prostate cancer: impact on cancer cell aggressiveness and tumor vasculature. Int J Med Sci. 2019; 16(1): 115-124, doi: 10.7150/ ijms.28735, indexed in Pubmed: 30662335.

33. Chen YK, Hou HA, Tang JL, et al. Clinical and prognostic implications of Roundabout 4 (robo4) in adult patients with acute myeloid leukemia. PLoS One. 2015; 10(3): e0119831, doi: 10.1371/journal.pone.0119831, indexed in Pubmed: 25794001.

34. Zhao H, Ahirwar DK, Oghumu S, et al. Endothelial Robo4 suppresses breast cancer growth and metastasis through regulation of tumor angiogenesis. Mol Oncol. 2016; 10(2): 272-281, doi: 10.1016/j.molonc.2015.10.007, indexed in Pubmed: 26778715.

35. Su C, Shi K, Cheng Xu, et al. Methylation of CLEC14A is associated with its expression and lung adenocarcinoma progression. J Cell Physiol. 2019; 234(3): 2954-2962, doi: 10.1002/jcp.27112, indexed in Pubmed: 30191970.

36. Krishna Priya S, Kumar K, Hiran KR, et al. Expression of a novel endothelial marker, C-type lectin 14A, in epithelial ovarian cancer and its prognostic significance. Int J Clin Oncol. 2017; 22(1): 107-117, doi: 10.1007/s10147-016-1033-6, indexed in Pubmed: 27567920.

37. Lone GN, Sheikh AA, Sheikh ZA, et al. Role of preoperative chemotherapy in squamous cell carcinoma of esophagus in kashmir, a cancer belt - a pilot study. Asian Pac J Cancer Prev. 2011; 12(2): 465-470, indexed in Pubmed: 21545214.

38. Ichikawa N, Kamiyama T, Yokoo H, et al. Preoperative chemotherapy in colorectal cancer patients with synchronous liver metastasis. Mol Clin Oncol. 2020; 12(4): 374-383, doi: 10.3892/mco.2020.1992, indexed in Pubmed: 32190322. 